\title{
Miguel de la Guardia and Salvador Garrigues (Eds.): Challenges in Green Analytical Chemistry
}

\author{
Ken Jones
}

Published online: 19 April 2012

(C) Springer-Verlag 2012

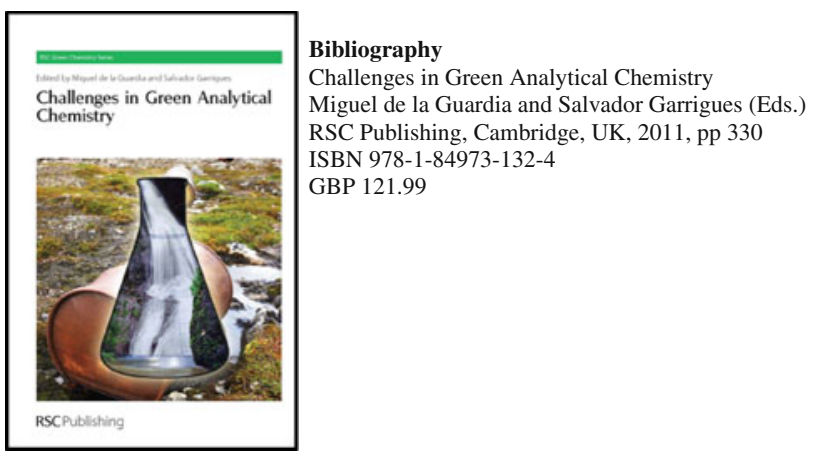

The term "green chemistry" would be regarded by many as an oxymoron, and yet many of these critics will turn to pharmaceutical products without any association that these also belong to the same family as the dreaded and betterknown polluters and defilers of the environment. Based on this premise the editors believe the best approach is to promote chemistry as "good" rather than "bad" and "green chemistry" is the preferred terminology. If only it were so simple: perceptions regrettably always outweigh facts.

Green analytical chemistry is integrated into the frame of green chemistry by adopting previously known clean methods of analysis, for example the use of highly efficient digestion systems for sample preparation, minimisation of analytical determinations, their automation and the on-line treatment of analytical wastes. Consisting of ten chapters, the subject matter does indeed cover the topics above, all multi-authored by specialists in their fields. There are two potential readerships; practicing analysts who have a desire to make their procedures greener and teachers of analytical chemistry who wish to introduce this modern concept into a generation that is likely to be more receptive.

Each chapter has been thoroughly researched and the described techniques have been carefully selected to achieve the aim of minimising potential pollution and waste whilst retaining efficiency and economy-but will for example manufacturers be persuaded to accept the costs of, for example, packing products into transparent containers such that non-invasive analysis can be achieved; will local managers, with an eye on the bottom line, switch to solvents costing twice as much as those currently in use?

Whilst GC is regarded as a relatively green separation process, HPLC is less so, the main culprit being the widespread use of acetonitrile. Even an average-in-use HPLC consumes about $250 \mathrm{~L}$ of acetonitrile annually and one chapter is devoted to minimising its use. Fortunately new instruments, largely driven by manufacturers, will in any event drive end-users into more efficient and economical methods.

The primary target is seen to be miniaturisation, where nanolitres and picolitres rather than microlitres and millilitres become the norm. The keys to this world are "worldto-chips", interfaces to connect microfluidic devices to the macro environment of the world, a problem awaiting a solution, that once found would really "green" analysis.

This collection will be useful to practicing analytical chemists by broadening their horizons to "what can be" rather than "what is". However, as always, if potential cost savings cannot be demonstrated to greatly exceed the cost of method development, then the less green method will be retained. 